\title{
Degradation of Ursolic Acid, a Major Component of Apple Wax, by a Pseudomonad Isolated from Soil
}

\author{
By L. HANKIN AND P. E. KOLATTUKUDY \\ Department of Biochemistry, The Connecticut Agricultural Experiment \\ Station, New Haven, Connecticut 06504, U.S.A.
}

(Accepted for publication 4 January 1969)

\begin{abstract}
SUMMARY
A Pseudomonas sp. isolated from orchard soil utilized ursolic acid $\left(\mathrm{C}_{30} \mathrm{H}_{48} \mathrm{O}_{3}\right)$, a major component of apple wax, as a sole source of carbon. It evolved ${ }^{14} \mathrm{CO}_{2}$ from $\left[{ }^{14} \mathrm{C}\right]$ ursolic acid and incorporated the label into all usual cell constituents; it formed a labelled polar metabolite of ursolic acid. Orchard soil thus contains at least one organism which is able to degrade the terpenes of the cuticular wax of plants.
\end{abstract}

\section{INTRODUCTION}

In the general ecological system of orchard land large amounts of plant materials such as leaves and fruits reach the soil and are degraded by soil organisms. These plant materials are covered with a complex mixture of hydrophobic chemical compounds usually referred to as plant waxes. Two major types of compounds in plant waxes are aliphatic hydrocarbons (and derivatives) of chain length $\mathrm{C}_{20}$ to $\mathrm{C}_{35}$, and alicyclic compounds such as triterpenes. Very little is known about the fate of these individual lipids in soil. We have already reported on the utilization of $n$-nonacosane, probably the most common paraffin in plant waxes, by animals (Kolattukudy \& Hankin, I966) and by a soil bacterium (Hankin \& Kolattukudy, I968).

Wax from fruits such as apple (Huelin \& Gallop, I95I), grape (Radler, I965; Radler \& Horn, 1965), pomegranate (Brieskorn \& Keskin, 1954) and many Japanese plants (Kariyini \& Hashimoto, I953) contain large proportions of terpenes such as ursolic and oleanolic acids. The terpenes are considered to be relatively stable. However, hardly any evidence of significant accumulation of these 'difficultly decomposable' lipids in productive agricultural soil has been noted (Stevenson, I966). It appears, therefore, that most agricultural soils contain micro-organisms able to utilize these materials. In this communication we describe the isolation of a bacterium from orchard soil, and the utilization by this organism of ursolic acid, a major component of apple wax.

\section{METHODS}

\section{Isolation of ursolic acid fraction from apples}

Apples collected from the Station experimental orchard were submerged for I min. in a large volume of boiling chloroform. The chloroform extract was concentrated in vacuo and hexane was added to precipitate the ursolic acid fraction. The precipitate was washed several times with hexane to remove as much of the aliphatic lipids as possible, dissolved in a minimum amount of hot isopropyl ether + acetone mixture $(7+3, v / v)$ and reprecipitated with hexane. Thin-layer chromatography (t.l.c.) on 
silica gel G with isopropyl ether +acetone $(7+3, \mathrm{v} / \mathrm{v})$ showed a single spot $\left(R_{F^{\prime}} 0.44\right)$ detected by stannic chloride spray (Waldi, 1965). Gas-liquid chromatography of the ursolic acid fraction (as the silyl ether) showed this material to be predominantly ursolic acid, but with a smaller quantity of a companion terpene which could not be resolved fully by t.l.c. The ursolic acid fraction was used for both isolation of the test organism and for growth studies. The procedure described yielded $4.5 \mathrm{~g}$. ursolic acid fraction from $4 \mathrm{~kg}$. of apples.

Preparation of $\left[{ }^{14} \mathrm{C}\right]$ ursolic acid. Apple skin sections, $\mathrm{I} 3 \mathrm{~mm}$. diam. and $\mathrm{I} \mathrm{mm}$. thick (cut from cork-borer plugs), were incubated with sodium $\left[{ }^{14} \mathrm{C}\right]$ acetate. A ratio of 43 apple skin slices to I m.c. of sodium $\left[{ }^{14} \mathrm{C}\right]$ acetate was used. During incubation the slices were exposed to $800 \mathrm{ft}$-candles of light at $29.5^{\circ}$ for $48 \mathrm{hr}$. At the end of the incubation period they were placed in a mixture of chloroform and methanol $2+\mathrm{I}$ (v/v). The lipid material was recovered (Folch, Lees \& Sloane-Stanley, 1957) and cold hexane added to precipitate the ursolic acid fraction. The precipitate was collected, washed with hexane, redissolved and reprecipitated. This crude ursolic acid fraction was placed on a silica gel column $(30 \mathrm{~cm} . \times \mathrm{I} \mathrm{cm}$.) and the column was washed first with hexane and then with a mixture of isopropyl ether and acetone $7+3(\mathrm{v} / \mathrm{v})$. The ether + acetone eluate was concentrated and ursolic acid precipitated with hexane. The precipitate was collected and washed with hexane. This fraction was further purified by repeated preparative t.l.c. on silica gel $G$ plates with isopropyl ether + acetone as the developing solvent. The radioactive area corresponding to ursolic acid was scraped off and the acid eluted with the same solvent. This $\left[{ }^{14} \mathrm{C}\right]$ ursolic acid was used for the metabolic studies.

Mineral medium. The basal medium used has previously been described (Hankin \& Kolattukudy, I968).

Ursolic acid medium. Ursolic acid (200 mg.) was dissolved in $100 \mathrm{ml}$. of hot acetone and kept warm on a steam bath. Mineral medium (200 ml.) was added slowly with continual stirring in a stream of nitrogen until all acetone was removed. The medium was refrigerated until used. Ursolic acid was added at the rate of $0 . \mathrm{I} \%, \mathrm{w} / \mathrm{v}$. in growth studies.

Isolation of test organism. To $50 \mathrm{ml}$. of sterile ursolic acid medium in $250 \mathrm{ml}$. Erlenmeyer flasks was added about a spoonful of either soil, leaves, or both, collected from the Station experimental orchard. The flasks were shaken at room temperature (22 to $23^{\circ}$ ) and each $24 \mathrm{hr}$ a loopful of culture fluid was examined for growth of organisms by staining. From flasks showing growth, $\mathrm{O} \cdot \mathrm{I} \mathrm{ml}$. of fluid was aseptically transferred to another flask of ursolic acid medium and incubated. Such transfers were repeated at least five times. The culture was then streaked on Trypticase Soy Agar plates (Baltimore Biological Laboratory, Baltimore, Md). After growth at room temperature, selected colonies were transferred into fresh medium. Upon evidence of growth, $0^{\circ} \mathrm{I} \mathrm{ml}$. of culture was transferred to fresh medium. At least nine such transfers were made. Conventional methods were used to determine purity of culture. The identification of the organism is described under results.

Determination of radioactivity. All radioactivity was determined as previously described (Kolattukudy, 1965). Counting was done with a standard deviation of less than $3 \%$. Internal standards of radioactive toluene were used to determine the efficiency of counting, which was usually $60 \%$.

Experiments with labelled ursolic acid. The test organism was grown for $24 \mathrm{hr}$ on 
agar slants (Trypticase Soy Agar) and the organisms harvested by centrifugation. The organisms were washed four times with $0.85 \%$ saline and finally suspended in I $\mathrm{ml}$. of mineral medium. These organisms were then used as inoculum for $25 \mathrm{ml}$. of mineral medium containing labelled $\left[{ }^{14} \mathrm{C}\right]$ ursolic acid $\left(2 \times 1 \mathrm{IO}^{7} \mathrm{c}\right.$.p.m. $)$. The contents of the flask were shaken at room temperature $\left(22\right.$ to $\left.23^{\circ}\right)$. Air was bubbled through the incubation mixture to remove ${ }^{14} \mathrm{CO}_{2}$ which was collected in a $10 \%(\mathrm{v} / \mathrm{v})$ solution of ethylenediamine in ethanol.

Since the evolution of ${ }^{14} \mathrm{CO}_{2}$ began to diminish after II hr, the experiment was terminated and the entire incubation mixture frozen and lyophilized in vacuo. The dried material was refluxed under nitrogen with a mixture of chloroform + methanol $(2+\mathrm{I}, \mathrm{v} / \mathrm{v})$ for $8 \mathrm{hr}$. The chloroform-soluble material was recovered after acidifying the mixture with $\mathrm{HCl}$ according to the method of Folch et al. (1957). The extracts obtained were concentrated in vacuo, made to volume and the radioactivity determined.

The chloroform-soluble material was dried in vacuo and applied to a preparative silica gel $\mathrm{G}$ thin layer plate which was developed with a mixture of isopropyl ether and acetone $(7+3 ; \mathrm{v} / \mathrm{v})$.

The water-soluble portion of the chloroform + methanol extract and the hydrolysed cell residue were separated into acidic, basic and neutral portions with Dowex 50 WX 8 resin and Dowex I C 8 resin. Hydrolysis of the cell residue was done with $5 \mathrm{~N}-\mathrm{HCl}$ in a sealed tube for $24 \mathrm{hr}$ at I I $0^{\circ}$. The complete hydrolysis of the neutral fractions was done with $6 \mathrm{~N}-\mathrm{HCl}$ in a sealed tube at $\mathrm{I}_{2} \mathrm{I}^{\circ}$ for $4 \mathrm{hr}$.

Paper chromatography. Descending paper chromatography of hydrolysed and unhydrolysed neutral fractions was done on Whatman no. I paper with butanol+ pyridine + water $(6+4+3)$ as the solvent system. Cationic fractions were analysed by chromatography on Chromar sheet (Mallinckrodt Chemical Co., St. Louis, Mo.) with butanol + acetic acid + water $(4+I+5)$.

\section{RESULTS}

Identification of test organism. The bacterium isolated from orchard soil which was able to utilize triterpenoid acids as a sole source of carbon was a Gram-negative motile rod with I to 3 polar flagella. It has been classified as a Pseudomonas sp. in the fluorescent group according to methods described by Stanier, Palleroni \& Doudoroff (1966). It showed the usual biochemical reactions described for this group.

Growth of Pseudomonas sp. The test organism was grown in $25 \mathrm{ml}$. of ursolic acid medium at 23,32 , and $35^{\circ}$ in shake culture. Initial count was $2 \cdot 8 \times \mathrm{IO}^{-5}$ organisms per ml. Total counts were made at selected intervals on Plate Count Agar (Difco). The growth curves obtained are shown in Fig. I. Since $23^{\circ}$ was found to be near the optimum, subsequent experiments were carried out at room temperature. We have also obtained good growth up to $30^{\circ}$.

Utilization of $\left[{ }^{14} C\right]$ ursolic acid by Pseudomonas sp. To demonstrate that this pseudomonad was able to catabolize ursolic acid $\left(\mathrm{C}_{30} \mathrm{H}_{48} \mathrm{O}_{3}\right)$, labelled ursolic acid was provided to the organism and the metabolic products were examined. As shown in Fig. 2, after a lag of several hours a linear rate of ${ }^{14} \mathrm{CO}_{2}$ evolution was observed. After II hr the rate of ${ }^{14} \mathrm{CO}_{2}$ evolution decreased. About II \% of the administered $\left[{ }^{14} \mathrm{C}\right]$ appeared in respiratory $\mathrm{CO}_{2}$ at the end of the experimental period (Table I). 
Water-soluble metabolites comprised about $8 \%$ of the administered radioactivity (Table I). The cell residue contained about $9 \%$ of the administered radioactivity and about $64 \%$ was in the chloroform-soluble material (Table I).

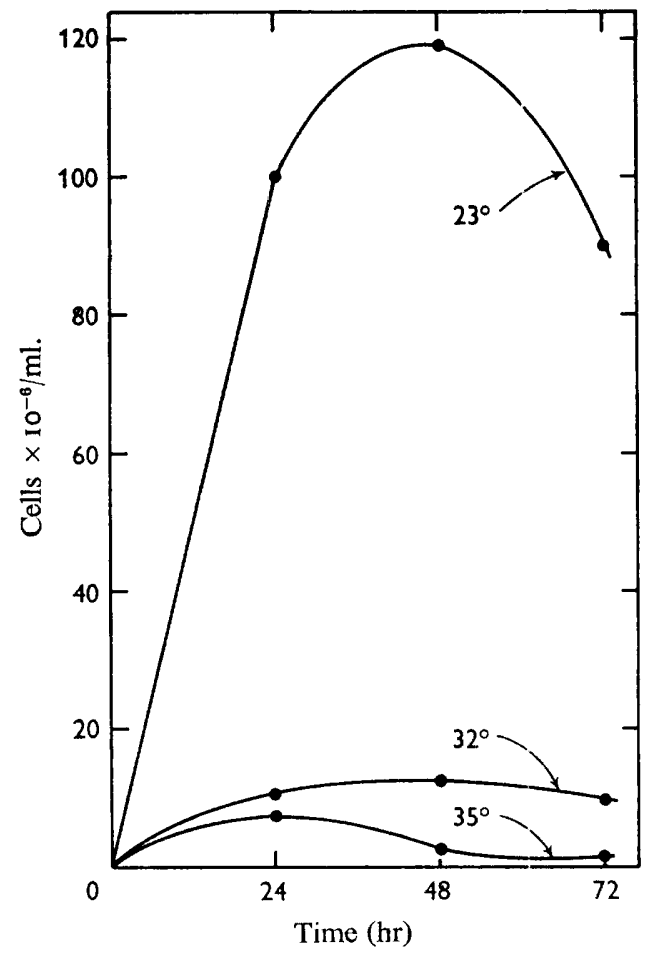

Fig. I

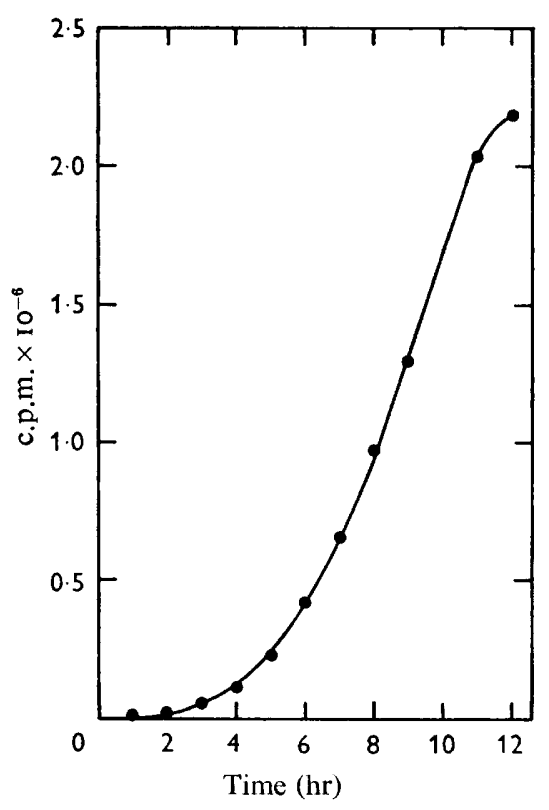

Fig. 2

Fig. I. Growth of a Pseudomonas sp. with ursolic acid as sole source of carbon.

Fig. 2. Production of ${ }^{14} \mathrm{CO}_{2}$ by a Pseudomomas sp. growing on $\left[{ }^{14} \mathrm{C}\right]$ ursolic acid.

Table I. Distribution of radioactivity $\left[{ }^{14} \mathrm{C}\right]$ in fractions from incubation mixture when the Pseudomonas sp. was grown with $\left[{ }^{14} \mathrm{C}\right]$ ursolic acid as sole source of carbon

Fraction

Chloroform soluble

Water soluble

Respiratory $\mathrm{CO}_{2}$

Cell residue

Acid hydrolysate**

Non-hydrolyzable

Recovery
Radioactivity $\%$ of (c.p.m. $\times 1 \mathrm{I}^{-6}$ ) administered

$\begin{array}{rr}12 \cdot 84 & 64.2 \\ 1 \cdot 58 & 7 \cdot 9 \\ 2 \cdot 17 & 10 \cdot 9 \\ & \\ 1 \cdot 22 & 6 \cdot 1 \\ 0.50 & 2 \cdot 5 \\ 18 \cdot 31 & 91 \cdot 6\end{array}$

* Hydrolysed with $5 \mathrm{~N}-\mathrm{HCl}$; sealed tube, $24 \mathrm{hr}$ at $1 \mathrm{IO}^{\circ}$.

The water-soluble metabolites and the acid hydrolysate of the cell residue were fractionated into cationic, anionic and neutral fractions, all of which contained significant radioactivity (Table 2). Among the water-soluble metabolites, neutral and anionic fractions accounted for the major part of the radioactivity. Paper chromato- 
graphy of the neutral fraction showed that it contained some labelled glucose, but the major part of the $\left[{ }^{14} \mathrm{C}\right]$ appeared to be in compounds with higher molecular weight. After acid hydrolysis most of the radioactivity was found in the region of glucose. In the cell-residue hydrolysate, on the other hand, the major part of the radioactivity was in the cationic fraction. The cationic material from the water-soluble fraction and the cell-residue hydrolysate were examined by paper electrophoresis and t.l.c. The usual spectrum of amino acids was found to be labelled.

Analysis of the chloroform fraction by t.l.c. showed that most of the radioactivity of this fraction $(89 \%)$ moved with the substrate. However, about I I \% remained at the origin and are designated as polar lipids. Analysis of the substrate showed no radioactivity in the polar lipid region.

Table 2. Fractionation of water-soluble materials from incubation mixture when the Pseudomonas sp. was grown with $\left[{ }^{14} \mathrm{C}\right]$ ursolic acid as sole source of carbon

$\begin{array}{ccc}\quad \text { Fraction } & \overbrace{\text { Water soluble }}^{\text {Radioactivity (c.p.m. } \times 1 \mathrm{ro}^{-6} \text { ) }} & \text { Cell residue } \\ \text { Cationic material } & 0.20 & 0.93 \\ \text { Anionic material } & 0.50 & 0.12 \\ \text { Neutral material } & 0.87 & 0.12\end{array}$

Analysis of polar lipids. Refluxing the polar lipid fraction with ethanolic $\mathrm{KOH}$ under nitrogen and subsequent analysis by t.l.c. with a developing solvent composed of a mixture of hexane, chloroform, methanol and formic acid $(60+35+10+2, v / v)$ indicated that the material is unchanged by this treatment $\left(R_{F} 0.2\right)$. In this same solvent system the methylated and acetylated polar lipids showed a slightly higher $\boldsymbol{R}_{\boldsymbol{r}}$ $(0.28)$, indicating that the polarilipid fraction is presumably a metabolic intermediate containing both hydroxyl and carboxyl groups.

\section{DISCUSSION}

The only organic material other than ursolic acid in the mineral medium was calcium pantothenate $(200 \mathrm{mg}$./1.) and this was insufficient to sustain growth of the test organism at the levels observed. Furthermore, almost half the $\left[{ }^{14} \mathrm{C}\right]$ of the administered labelled ursolic acid appeared in the various metabolites. In view of the control experiments and the analysis of the substrate itself, the amounts of radioactivity found in the metabolites cannot possibly be attributed to an impurity that might have been present in the substrate. These results therefore prove that the pseudomonad degraded ursolic acid, the major terpene of apple wax.

It is generally held that the cuticular waxes from plants accumulate in the soil. Although the biodegradability of these materials is undoubtedly less than that of other plant constituents, they must undergo some degradation by soil organisms to account for the relatively small amounts of such compounds found in orchard soil (Stevenson, 1966). The pseudomonad we isolated grew well on the ursolic acid fraction of the apple wax. Probably the organism we have isolated is only one of many present in soil which can degrade the terpene fraction of cuticular lipids. 
We thank Mr J. Redys, Laboratory Division, Connecticut State Department of Health, Hartford, for help in the identification of the test organism, Mr J. Marcucci for technical assistance and Miss Katherine Clark for preparation of the figures.

\section{REFERENCES}

Brieskorn, C. H. \& Keskin, M. (1954). Über das Vorkommen von Triterpenen in der Stammrinde, der Fruchtschale und dem Blatte von Pumia granatum L. Pharm. Acta Helv. 29, 338.

Folch, J., Lees, M. \& Sloane-Stanley, G. H. (1957). A simple method for the isolation and purification of total lipids from animal tissues. J. biol. Chem. 226, 497.

Hankin, L. \& KolatTukUdy, P. E. (1958). Metabolism of a plant wax paraffin ( $n$-nonacosane) by a soil bacterium (Micrococcus cerificans) J. gen. Microbiol. 51, 457.

Huelin, F. E. \& Gallop, R. A. (195I). Studies in the natural coating of apples. I. Preparation and properties of fractions. Aust. J. sci. Res. Ser. B 4, 526.

KaRIYINI, T. \& HaShimoto, Y. (I953). Chemical components of plant cuticle with special reference to triterpenoid constituents. Experientia 9, I 36.

Kolattukudy, P. E. (1965). Biosynthesis of wax in Brassica oleracea. Biochemistry, N.Y. 4, I 844.

KolatTuKUdy, P. E. \& HANKIN, L. (1966). Metabolism of a plant wax paraffin ( $n$-nonacosane) in the rat. J. Nutr. 90, I67.

Radler, F. (1965). The surface waxes of the Sultana Vine (Vitis vinifera cv. Thompson Seedless). Aust. J. biol. Sci. 18, 1045.

Radler, F. \& Horn, D. H. S. (1965). The composition of grape cuticle wax. Aust. J. Chem. 18, 1059.

Stanier, R. Y., Palleroni, N. J. \& Doudoroff, M. (I966). The aerobic pseudomonads: a taxonomic study. J. gen. Microbiol. 43, I59.

Stevenson, F. J. (1966). Lipids in soil. J. Am. Oil Chem. Soc. 43, 203.

WALDI, D. (1965). Spray reagents for thin-layer chromatography. In Thin-layer Chromatography, a Laboratory Hand Book, p. 483. Ed. by E. Stahl, New York: Academic Press, Inc. 